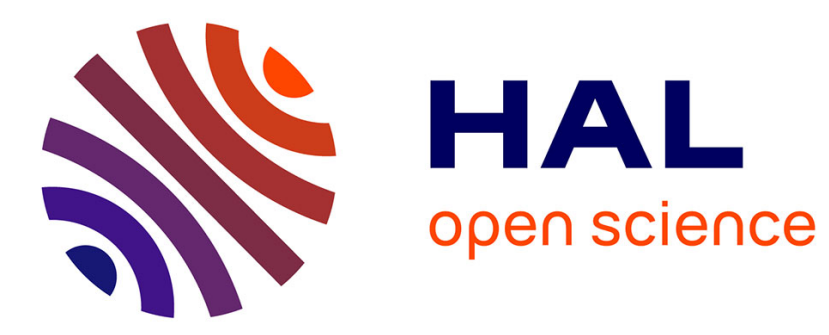

\title{
Behavioral ethics: how psychology influenced economics and how economics might inform psychology?
}

Bernd Irlenbusch, Marie Claire Villeval

\section{To cite this version:}

Bernd Irlenbusch, Marie Claire Villeval. Behavioral ethics: how psychology influenced economics and how economics might inform psychology?. Current Opinion in Psychology, 2015, 6, pp. 87-92. 10.1016/j.copsyc.2015.04.004 . halshs-01159696

\section{HAL Id: halshs-01159696 \\ https://shs.hal.science/halshs-01159696}

Submitted on 3 Jun 2015

HAL is a multi-disciplinary open access archive for the deposit and dissemination of scientific research documents, whether they are published or not. The documents may come from teaching and research institutions in France or abroad, or from public or private research centers.
L'archive ouverte pluridisciplinaire HAL, est destinée au dépôt et à la diffusion de documents scientifiques de niveau recherche, publiés ou non, émanant des établissements d'enseignement et de recherche français ou étrangers, des laboratoires publics ou privés. 


\title{
Behavioral ethics: how psychology influenced economics and how economics might inform psychology?
}

\author{
Bernd Irlenbusch $^{\mathrm{a}}$ and Marie Claire Villeval ${ }^{\mathrm{b}}$ \\ Submitted to Current Opinion in Psychology
}

This version: 16 April 2015

\begin{abstract}
This review surveys recent research developed in behavioral economics on the determinants of unethical behavior. Most recent progress has been made in three directions: the understanding of the importance of moral norms in individual decision-making, the conflicting role of opportunities provided by asymmetries of information and social preferences, and the crucial effect of rules, occupational norms and incentive schemes in the diffusion of dishonesty. The connection between economics and psychology is the most vivid on the first dimension.
\end{abstract}

${ }^{a}$ University of Cologne, Department of Corporate Development and Business Ethics, AlbertusMagnus-Platz, 50923 Cologne, Germany. E-mail: irlenbusch@wiso.uni-koeln.de

${ }^{\mathrm{b}}$ Université de Lyon, Lyon, F-69007, France; CNRS, GATE Lyon Saint-Etienne, 93 Chemin des Mouilles, 69130, Ecully, France; CORTEX Labex (ANR-11-LABX-0042); IZA, Bonn, Germany. E-mail: villeval@gate.cnrs.fr 


\section{Introduction}

For decades, economists have analyzed dishonesty using the economics-of-crime approach of Becker (1968) [1]. Its main prediction is that rational individuals decide to commit a crime if the marginal benefits deriving from the dishonest action exceed its marginal costs, e.g. caused by expected punishment. Since the seventies numerous studies on tax evasion or corruption have shown that, indeed, people are reactive to variations in income, tax rates, probability of detection and level of sanctions. But they also repeatedly noticed that individuals cheat much less than what would be required by the maximization of income, emphasizing that compliance decisions should not be considered as pure gambles. It is more recently that economists have investigated the behavioral determinants of dishonesty. This topic is one of those where the dialogue between economists and psychologists is today the most active (see, for example, the 2013 special issue on deception of the Journal of Economic Behavior \& Organization) [2].

In this note, we present recent economic research on dishonesty along three main lines, from the more to the less connected with psychology. We start with the analysis of individual ethical behavior and moral preferences, where the preoccupations of psychologists and economists meet the most closely. Then, we introduce research on dishonesty with strategic interactions and social preferences, where the specificity of economists is the focus on asymmetries of information and externalities of individual behavior on others' wellbeing. Finally, we present the analysis of the impact of institutions, rules and incentives on unethical behavior. This final set of results is especially relevant to economists since their interest for the determinants of dishonesty is partly motivated by the willingness to design more efficient policies. Note the contrast with previous surveys on dishonesty (see notably [3]), because we mainly consider papers published since 2012 and we do not discriminate between methodological aspects. We primarily focus on deceptive behavior and only marginally discuss other behavioral ethics topics like altruism, reciprocity, justice and fairness.

\section{Ethical behavior and moral preferences in non-strategic environments}

In the traditional economics-of-crime framework, individuals facing similar economic conditions should only vary in their decision to lie because of different risk attitudes. However, inspired by psychology, recent behavioral economics research has delivered two major sets of results that can hardly be rationalized within the standard framework.

First, even when there is no risk of detection and no sanction there is a huge heterogeneity in the individuals' decision to act dishonestly. Using a representative sample of the population, an experiment in which people could earn money by reporting on the phone the outcome of a coin toss has revealed almost no difference between the distribution of reports and the distribution of fair tosses, suggesting that people have high moral lying costs [4]. This was particularly true when the reporting decision was taken after a relative extensive interaction period as it was implemented in this study between the interviewer and the subject. The fact that not all people lie to maximize their earnings has been observed in adults but also to a much smaller extent in children $[5,6]$, suggesting that it needs time to learn and progressively internalize moral norms.

Heterogeneity of decisions indicates that individuals differ in their preferences. In [7], Gibson, Tanner and Wagner contrast a type-based model in which individuals' type is either economic or ethical and an approach of consequentialists (who care only about outcomes) and non-consequentialists (who - irrespective of the consequences - feel resistance to engage in 
actions that would violate moral values, e.g. who feel a pure lying aversion [8]). The observed decrease of the lying rate with higher truthfulness costs is inconsistent with a bipolar typebased model and suggests instead a continuum of preferences for truthfulness. For a given monetary cost of honesty, variations in behavior capture between-subject heterogeneity in moral costs. The non-separability between intrinsic and extrinsic costs reveals that heterogeneity exists also within individuals. This within-individual heterogeneity could explain that similar experiments deliver conflicting results, for example, on gender effects: recent evidence $[9,10]$ fails replicating the higher males' propensity to deceive found in [11]. Lying, nevertheless, seems to be more pronounced in male and mixed groups compared to female groups [12].

The second set of results that contradicts the standard economic model is the evidence of incomplete dishonesty, suggesting non linearities in moral costs. An important contribution has been made in [13] by Fischbacher and Föllmi-Heusi who ask subjects to report the outcome of a die roll in order to determine payoffs. Besides a fraction of subjects who report truthfully and a fraction who maximize earnings by lying in full, a majority of people cheat but incompletely, and this is robust to several manipulations. Similar results have been found under reinforced privacy, using the dice-under-the-cup paradigm [14]. In a task involving counting various types of coins, a small theft rate of $10 \%$ did also not change when monitoring of a different dimension - in this case quality of the work - was introduced [15]. In line with [16], partial cheating can be explained by the willingness of people to exploit earnings opportunities while maintaining their self-concept of honesty. Most people value appearing moral: they cheat up to the threshold above which they would have to admit they are dishonest. Interestingly, people may sometimes lie even disadvantageously to appear honest, as in an experiment conducted with nuns [17].

However, individuals can manipulate their moral firmness, consciously or unconsciously. Both psychologists and economists analyze which self-serving strategies people use to manage self-image and reduce the moral cost of lying. Individuals create self-justification to lie, by managing attention or reframing the decision problem $[14,18,19,20]$. They engage in moral balancing, by behaving more generously after cheating [21,22]. Self-serving rationalizations also include focusing on the benefits one's lie causes to others $[23,24]$.

\section{Lying, social preferences and strategic interactions}

Dishonest actions go rarely without social consequences. They usually generate positive or negative externalities on others' well-being through social interactions. Therefore, social preferences (such as fairness, inequality aversion, efficiency or social image concerns) are expected to interact with deceptive behavior. People with social preferences misbehave or not, depending both on the harm or benefit a lie causes to others, and on the weight they put on others' utility in their own utility function. This relationship is complex. On the one hand, as shown by Gneezy in [25], there is heterogeneity in the willingness to lie when a lie hurts others [26]. People dislike not keeping their promises and guilt aversion prevents deception $[27,28]$. This may explain that people are more willing to lie about information they hold than about their actions [29]. It has also been shown that social image concerns and shame increase taxpayers' compliance when detected evasion is publicly exposed [30,31]. On the other hand, people can ignore the consequences of their lie when it is easy to pretend not paying attention like when not returning change in a restaurant [32]. When the incentive to lie is strong enough, the observability of deception does not prevent people to lie even in front of their victim [33], which may be reinforced by the fact that people dislike denouncing cheaters [34]. It has also been found that people with social preferences are more likely to tell black lies 
when they feel they have been treated unfairly in the past [35].

The role of social preferences is also complex when lies help others, creating a moral dilemma for people with lying aversion. On the one hand, oxytocin has been shown to promote group-serving dishonesty [36], and a fraction of individuals are willing to tell altruistic white lies, i.e. lies that help others but require a personal sacrifice [37]. On the other hand, in [37] Erat and Gneezy show that a large fraction of people, regardless of their social preferences, are not willing to tell even Pareto white lies, i.e. lies that increase the payoff of both players.

If many people dislike lying when it reduces others' wellbeing, there is also ample evidence of strategic exploitation of asymmetries of information. This is the case on markets for credence goods for which sellers are better informed than buyers on the true quality of the goods, even ex post, like in medical or judicial services, car or computer repair. In a field experiment on taxi rides [38], Balafoutas, Beck, Kerschbamer and Sutter manipulate the degree of presumed familiarity of clients on the ride and find longer detours and undue extracharges when the client seems to be less informed. Overtreatment and overcharging have been found also with car mechanics [39]. The abuse of hierarchical positions in social interactions is another source of unethical behavior, notably through biased evaluation of employees [40].

People develop strategies to reconcile the exploitation of enrichment opportunities with the protection of their self-concept of honesty in a social environment. They can evade culpability by delegating the responsibility to an agent [41]. Delegation of lying is even more likely when the lie harms a victim to a greater extent [42]. Keeping a good image of oneself when cheating may also be easier when one exploits the moral wiggle room by remaining strategically ignorant about potential bad consequences of own actions for others. Remaining strategically ignorant not only helps to preserve a better self-concept but might even deflect punishment when interacting with others $[43,44]$. Interestingly, people seem to shy away from exploiting the moral wiggle room when they feel obliged to reciprocate [45]. In ultimatum games where the proposer has private information about the pie size there are differences in explicit and implicit deception. When the private information can be misrepresented through untruthful statements (explicit deception) or through information-revealing actions (implicit deception) it is found that requiring informed parties to make an explicit statement yields greater deception than when information is communicated implicitly [46].

Deception might also be easier when one can persuade oneself that peers would lie in the same circumstances. Asymmetric peer effects have indeed been identified notably in the domain of tax evasion. Consistent with the "broken windows effect", a bad example from others has a stronger impact on compliance than a good example [47]. Dishonesty is indeed contagious and the permeability of behavior could explain that some groups are characterized by a high degree of honesty and others by prevalent dishonesty $[48,49]$.

\section{How rules and institutions influence unethical behavior}

Dishonesty is not observed at the same degree across environments. Indeed, morals are also shaped by institutions, cultures and incentives.

If people tend to stretch the truth and thus their moral responsibility, then institutional policy interventions reducing the moral wiggle room might be successful. One policy intervention is monitoring regulation. The opportunity to avoid being submitted to regulations increases unethical conduct compared to situations in which regulation is either exogenously imposed or entirely absent [24]. A field experiment on selling newspapers on the street shows that the intensive margin of customers' honesty is positively impacted by a moral appeal for 
honesty but not by a legal reminder [50]. The effectiveness of moral suasion is also documented in [51]. This confirms the importance of internalized moral norms.

Market interactions are suspected to erode moral values. In [52] Falk and Szech report the results of an experiment in which individuals could either earn money and let a laboratory mouse be sacrificed, or renounce the money for saving the mouse's life. In bilateral and multilateral double auction market institutions sellers and buyers could bargain to determine the price of the trade between life and money. They could alternatively decide not to bargain and save the mouse's life. It turns out that with market institutions, a much higher percentage of subjects are willing to trade for prices below or equal to the fixed earnings. This higher willingness to kill in market interactions seems to indicate that markets erode moral values. This may result from social learning of prevailing norms through market interactions, a stronger focus on materialistic values, or the dilution of individual responsibility.

Markets should, however, not be associated unconditionally with moral decay. The success of socially responsible products shows that a fraction of people are willing to pay a higher price in exchange for a reduction of negative externalities, and this resists to competitive pressure. But markets are embedded in cultures. With a comparison between China and Switzerland, in [53] Bartling, Weber and Yao show that if individuals from various cultures may derive the same utility from reducing negative externalities in a non-market context, market participants vary a lot in their willingness to internalize the social costs of trading activities. It is therefore the combination of market exchanges and culture that may crowd-out moral values, some cultures favoring high moral values, others not.

Indeed, if market exchanges put more emphasis on materialistic values, culture may either strengthen or weaken moral values. Priming participants in a market context increases the proportion of lies, albeit not significantly so [54]. Priming business culture favors dishonesty in the banking industry [55]. While bankers behaved as honestly as other players in a control condition, making their professional identity more salient increased their dishonesty. Similar priming or increased money salience did not trigger dishonesty in other occupations. A dual process is probably at work: a dishonest business culture may lead individuals to adopt morally weak norms because of de-individualization; but a weak culture may also let individual misconduct permeate organizations through social interactions [56]. Culture, however, does not affect all organizational members the same. When personal ethical opinions do not match group norms, this mismatch can correlate with job dissatisfaction and lying [57].

Professional cultures are also shaped by systems of incentives, some of them crowding in and others crowding out honesty. Introducing asymmetric liability where bribe-takers are culpable but bribe-givers have legal immunity reduces corrupt practices [58]. When prizes are assigned based on competitors' relative performance, increasing the spread between the winner's and the loser's prizes encourages misconduct [59]. Not only competitive rewards increase dishonesty in comparison with individual rewards [60], more dishonest people are also more likely to self-select in competitive environments where deception is possible [61]. Note that other types of incentives, based for example on team rewards, are not dishonesty immune $[62,63,64,65]$. And competition needs not involve monetary rewards to generate dishonesty: even fixed rewards may encourage misconduct if individuals are willing to compete for rank and status [66], and people cheat for prestige incentives [67]. In contrast, shifting subjects' attention from money (or perhaps performance) into time reduces cheating [68], which is consistent with both findings that time matters in honesty because self-serving behavior tends to be automatic [69], and that dishonesty is reduced when rewards from lying are delayed [70]. 


\section{Conclusion}

The literature on dishonesty has bloomed in recent years. Following psychologists but starting from a different perspective of standard models of rational cheating, economists have produced substantial experimental evidence on (dis-)honesty. The literature in economics and psychology has confirmed that even when there is (almost) no risk of detection, lying is incomplete and not universal, revealing the heterogeneity of moral costs and rejecting the simplistic standard economics-of-crime model.

The more specific dimensions of recent economic research are twofold. First, if moral costs interact with the extrinsic benefit of cheating, in strategic interactions this relationship is affected by the existence of pro- and anti-social preferences, concerns for status and norms, and asymmetric information. Second, the economic analysis of unethical behavior emphasizes the importance of institutions and incentives on the individuals' propensity to cheat, with certain rules or organizational modes more likely than others to bend moral firmness.

These findings open new challenges. One is producing alternative theoretical models of (un-)ethical behavior [71]. Another one is deriving policy implications to design more efficient rules and incentives to combat unethical behavior. This includes reflections on how to nudge people so that they prefer keeping a good image of themselves rather than trading off a small monetary benefit for a bigger loss of self-concept. Another major challenge is building a behavioral ethics approach able to bridge and fertilize knowledge from psychology, economics, neuroeconomics (see [72] on pupil dilation, [73] on hormones or [29] on emotions on cheating), and other social sciences.

\section{Conflict of interest statement}

Nothing declared.

\section{References and recommended reading}

1. Becker, G. S. (1968). Crime and punishment: An economic approach. Journal of Political Economy 76, 169-217.

2. Journal of Economic Behavior \& Organization (2013). Special issue on Deception, Incentives, and Behaviour, 93, 196-414.

3. Rosenbaum, S.M., Billinger, S., Stieglitz, N. (2014). Let's be honest: A review of experimental evidence of honesty and truth-telling. Journal of Economic Psychology 45, 181-196.

4. Abeler, J., Becker, A., Falk, A. (2014). Representative evidence on lying costs. Journal of Public Economics 113, 96-104.

5. Bucciol, A., Piovesan, M. (2011). Luck or cheating? A field experiment on honesty with children. Journal of Economic Psychology 32, 73-78. 6. Glätze-Rützler, D., Lergetporer, P. (2015). Lying and age: an experimental study. Journal of Economic Psychology 46, 1225.

7. * Gibson, R., Tanner, C., Wagner, A. F. (2013). Preferences for truthfulness: Heterogeneity among and within individuals. American Economic Review 103, 532-548.

Using individual decision situations in the lab the authors find that $32 \%$ of the subjects do 
not lie although they should according to the standard economic model. The percentage of subjects who are honest, however, decreases with the forgone gain from being truthful. This indicates that subjects do not simply belong to one of two types: those who lie when it is beneficial and those who never lie. The variation in lying can largely be explained by a measure of intrinsic lying aversion but within subjects this measure cannot be separated from the foregone economic gains, indicating that the preference for truthfulness also varies within subjects.

8. López-Pérez, R., Spiegelmann, E. (2013). Why do people tell the truth? Experimental Evidence for Pure Lie Aversion. Experimental Economics 16, 233-247.

9. Childs, J. (2012). Gender differences in lying. Economics Letters 114, 147-149.

10. Gylfason, H. F., Arnardottir, A. A., Kristinsson, K. (2013). More on gender differences in lying. Economic Letters 119, 94-96.

11. Dreber, A., Johanneson, M. (2008). Gender differences in deception. Economic Letters 99, 197-199.

12. Muehlheusser, G., Roider, A., Wallmeier, N. (2015). Gender differences in honesty: Groups versus individuals. Economics Letters 128, 25-29.

13. ** Fischbacher, U., Föllmi-Heusi, F. (2013). Lies in disguise: An experimental study on cheating. Journal of the European Economic Association 11, 525-547.

By making use of a private die rolling task in the lab the authors find that $39 \%$ of inexperienced subjects are fully honest and about $20 \%$ lie to maximize earnings. Many are partial liars. This finding is robust when stake size, externalities, and anonymity are varied. The authors provide evidence that partial lying is motivated to disguise lying which is consistent with the desire to maintain a positive self-concept.

14. Shalvi, S., Dana, J., Handgraaf, M.J.J., De Dreu, C.K.W. (2011). Justified ethicality: observing desired counterfactuals modifies ethical perceptions and behavior.

Organizational Behavior and Human Decision Processes 115, 181-190.

15. Belot, M., Schröder, M. (in press) The Spillover Effects of Monitoring: A Field Experiment. Management Science.

16. Mazar, N., Amir, O., Ariely, D. (2008). The dishonesty of honest people: A theory of selfconcept maintenance. Journal of Marketing Research 45, 633-644.

17. Utikal, V., Fischbacher, U. (2013). Disadvantageous lies in individual decisions. Journal of Economic Behavior \& Organization, 85, 108-111.

18. Ariely, D. 2012. The (Honest) Truth About Dishonesty. New-York: Harper Collins Publishers.

19. Gino, F., Ayal, S., Ariely, D. (2013). Self-serving altruism? The lure of unethical actions that benefit others. Journal of Economic Behavior \& Organization 93, 285-292.

20. Pittarello, A., Leib, M., Gordon-Hecker, T., Shalvi, S. (in press). See what you want to see: justifications shape ethical blind spots. Psychological Science.

21. Ploner, M., Regner, T. (2013). Self-image and moral balancing: An experimental analysis. Journal of Economic Behavior \& Organization 93, 374-383.

22. Gneezy, U., Imas, A., Madarász, K. (2014). Conscience Accounting: Emotion Dynamics and Social Behavior. Management Science 60 (11), 2645-2658.

23. Lewis, A., Bardis, A., Flint, C., Mason, C., Smith, N., Tickle, C., Zinser, J. (2012). 
Drawing the line somewhere: An experimental study of moral compromise. Journal of Economic Psychology 33 (4), 718-725.

24. Gino, F., Krupka, E.L., Weber, R.A. (2013). License to Cheat: Voluntary Regulation and Ethical Behavior. Management Science 59 (10), 2187-2203.

25. Gneezy, U. (2005). Deception: The role of consequences. American Economic Review, 95, 384-394.

26. Gneezy, U., Rockenbach, B., Serra-Garcia, M. (2013). Measuring lying aversion. Journal of Economic Behavior \& Organization 93, 293-300.

27. Charness, G., Dufwenberg, M. (2006). Promises and partnership. Econometrica 74(6), 1579-1601.

28. Ellingsen, T., Johannesson, M., Tjøtta, S., Torsvik G. (2010). Testing guilt aversion. Games and Economic Behavior 68, 95-107.

29. Serra-Garcia, M., Potters, J., van Damme, E. (2013). Lying about what you know, or about what you do? Journal of the European Economic Association 11 (5), 1204-1229.

30. Coricelli, G., M. Joffily, C. Montmarquette, M.C. Villeval (2010). Cheating, Emotions and Rationality: An Experiment on Tax Evasion. Experimental Economics 13, 226-247.

31. Coricelli, G., Rusconi, E., Villeval, M.C. (2014). Tax Evasion and emotions in repeated interactions: An empirical test of re-integrative shaming theory. Journal of Economic Psychology 40, 49-61.

32. Azar, O.H., Shira , Y., Bar-Eli, M. (2013). Do customers return excessive change in a restaurant?, Journal of Economic Behavior \& Organization 93, 219-226.

33. Van de Ven, J., Villeval, M.C. (In press). Dishonesty under scrutiny. The Journal of the Economic Science Association.

34. Reuben, E., Stephenson, M. (2013). Nobody likes a rat: on the Willingness to report lies and the consequences thereof. Journal of Economic Behavior \& Organization 93, 384-391.

35. Houser, D., Vetter, S., Winter, J. (2012). Fairness and cheating. European Economic Review 56 (8), 1645-1655.

36. Shalvi, S., de Dreu, C.K.W. (2014). Oxytocin promotes group-serving dishonesty. Proceedings of the National Academy of Sciences 111 (15), 5503-5507.

37. ** Erat, S., Gneezy, U. (2012). White lies. Management Science 58, 723-733.

The authors investigate lying behavior in a simple sender/receiver lab setting when lies are "altruistic white lies" (lies that benefit somebody else but are costly for the liar) or "Pareto white lies" (lies that benefit all). A significant fraction of senders turn out to lie when the costs for the sender are comparatively small compared to the benefit of the receiver. On the other hand, a significant fraction of senders do not lie even if the lie would benefit both.

38. * Balafoutas, L., Beck, A., Kerschbamer, R., Sutter, M. (2013). What drives taxi drivers? A field experiment on fraud in a market for credence goods. Review of Economic Studies 80, 876-891.

In a field experiment the authors study fraudulent behavior regarding the provision of credence goods which are characterized by information asymmetries between sellers and buyers. The authors find that taxi drivers in Athens, Greece, take passengers conveying the impression of being unfamiliar with the city on average on detours of almost double length compared to passengers who did not convey this impression. Passengers presumably 
perceived as unfamiliar with the tariff system (those speaking English) were overcharged in $22 \%$ of cases, while this happened only to $6 \%$ of the passengers in the role of a Greek citizen.

39. Beck, A., Kerschbamer, R., Qiu, J., Sutter, M. (2014). Car mechanics in the lab Investigating the behavior of real experts on experimental markets for credence goods. Journal of Economic Behavior \& Organization 108, 166-173.

40. Rosaz, J., Villeval, M.C. (2012). Lies and Biased Evaluation: A Real-Effort Experiment. Journal of Economic Behavior \& Organization 84 (2), 537-549.

41. Bartling, B., Fischbacher, U. (2012). Shifting the Blame: On Delegation and Responsibility. Review of Economic Studies 79 (1), 67-87.

42. Erat, S. (2013). Avoiding lying: The case of delegated deception. Journal of Economic Behavior \& Organization 93, 273-278.

43. Conrads, J, Irlenbusch, B. (2013). Strategic ignorance in ultimatum bargaining. Journal of Economic Behavior \& Organization 92, 104-115.

44. Bartling, B., Engl, F, Weber, R.A. (2014). Does Willful Ignorance Deflect Punishment? An Experimental Study. European Economic Review 70, 512-524.

45. Van der Weele, J.J., Kulisa, J., Kosfeld, M., Friebel, G. (2014). Resisting Moral Wiggle Room: How Robust Is Reciprocal Behavior? American Economic Journal: Microeconomics 6 (3), 256-264.

46. Kriss, P.H., Nagel, R., Weber, R.A. (2013). Implicit vs. explicit deception in ultimatum games with incomplete information. Journal of Economic Behavior \& Organization 93, 337-346.

47. Lefebvre, M., Pestieau, P., Riedl, A., Villeval, M.C. (in press). Tax Evasion and Social Information: An Experiment in Belgium, France and the Netherlands. International Tax and Public Finance.

48. Innes, R., Mitra, A. (2013). Is dishonesty contagious? Economic Inquiry 51, 722-734.

49. Fosgaard, T.R., Hansen, L.G., Piovesan, M. (2013). Separating Will from Grace: An experiment on conformity and awareness in cheating. Journal of Economic Behavior \& Organization 93, 279-284.

50. Pruckner, G. J., Sausgruber, R. (2013). Honesty on the streets: A field study on newspaper purchasing. Journal of the European Economic Association 11 (3), 661-679.

51. Dal Bó, E., Dal Bó, P. (2014) "Do the Right Thing:" The Effects of Moral Suasion on Cooperation. Journal of Public Economics 117, 28-38.

52. * Falk, A., Szech, N. (2013). Morals and Markets. Science 340(6133), 707-711.

The authors aim to investigate whether market interaction erodes moral values. They do this by means of a lab study in which subjects had the choice between receiving money for allowing a (laboratory) mouse to be killed or forgoing the money and saving the mouse. The fractions of subjects who were willing to kill a mouse to earn a monetary amount below or equal to 10 euros turn out to be significantly higher in two market treatments compare to an "individual" treatment.

53. * Bartling, B., Weber, R., Yao, L. (2015). Do markets erode social responsibility? Quarterly Journal of Economics 130 (1), 219-266. 
In laboratory product markets - conducted in Switzerland - with low-cost production that creates a negative externality for third parties, and an alternative production with higher costs and mitigated externality, consumers and firms turn out to avoid negative social impact in the market (both in terms of product types and in price premium for socially responsible products). Low-cost production with negative externalities is significantly more prevalent in markets conducted in China.

54. Cappelen, A. W., Sørensen, E. Ø., Tungodden, B. (2013). When do we lie? Journal of Economic Behavior \& Organization 93, 258-265.

55. * Cohn, A., Fehr, E., Marechal, M. (2014). Business culture and dishonesty in the banking industry. Nature 516, 86-89.

Bank employees are randomly assigned to one of two laboratory treatments that make their professional identity salient or not. In a second stage all subjects perform a coin tossing and reporting task to measure dishonesty. Bank employees are more dishonest in the treatment in which their professional identity is salient compared to when it is not. This is true with respect to the higher fraction of participants who report the maximal earning and also regarding incomplete lying.

56. Villeval M.C. (2014). Professional identity can increase dishonesty, Nature 516, 48-49.

57. Burks, S,V., Krupka, E.L. (2012). A Multimethod Approach to Identifying Norms and Normative Expectations Within a Corporate Hierarchy: Evidence from the Financial Services Industry. Management Science 58 (1), 203-217.

58. Abbink, K., Dasgupta, U., Gangadharan, L., Jain, T. (2014). Letting the briber go free: An experiment on mitigating harassment bribes. Journal of Public Economics 111, 17-28.

59. Conrads, J., Irlenbusch, B., Rilke, R. M., Schielke, A., Walkowitz, G. (2014). Honesty in tournaments. Economics Letters 123, 90-93.

60. Belot, M., Schröder, M. (2013). Sloppy work, lies and theft: A novel experimental design to study counterproductive behavior, Journal of Economic Behavior \& Organization 93, $233-238$.

61. Faravelli, M., Friesen, L., Gangadharan, L. (in press). Selection, tournaments, and dishonesty. Forthcoming in Journal of Economic Behavior \& Organization.

62. Briggs, K., Workman, J.P. and York, A.S. (2013). Collaboration to Cheat: A Game Theoretic Exploration of Academic Dishonesty in Teams. Academy of Management Learning \& Education 12 (1), 4-17.

63. Conrads, J., Irlenbusch, B., Rilke, R. M., Walkowitz, G. (2013). Lying and team incentives. Journal of Economic Psychology 34, 1-7.

64. Danilov, A., Biemann, T., Kring, T., Sliwka, D. (2013). The dark side of team incentives: Experimental evidence on advice quality from financial service professionals. Journal of Economic Behavior \& Organization 93, 266-272.

65. Morgulev, Azar, Lidor, Sabag, Bar-Elia (2014). Deception and decision making in professional basketball: Is it beneficial to flop? Journal of Economic Behavior \& Organization 102, 108-118.

66. Charness, G., Masclet, D., Villeval M.C. (2014). The dark side of competition for status. Management Science 60 (1), 38-55.

67. Pascual-Ezama, D., Prelec, D., Dunfield, D. (2013). Motivation, money, prestige and cheats. Journal of Economic Behavior \& Organization 93, 367-373. 
68. Gino, F., Mogilner, C. (2014). Time, money, and morality. Psychological Science, 25, 414-421.

69. Shalvi, S., Eldar, O., Bereby-Meyer, O. (2012). Honesty requires time (and lack of justifications). Psychological Science 23 (10), 1264-1270.

70. Ruffle, B. J., Tobol, Y. (2014). Honest on Mondays: Honesty and the temporal separation between decisions and payoffs. European Economic Review 65,126-135.

71. Kartik, N., Tercieux, O., Holden, R. (2014). Simple mechanisms and preferences for honesty. Games and Economic Behavior 83, 284-290.

72. Wang, J.T., Spezio, M., Camerer, C.F. (2010). Pinocchio's Pupil: Using Eyetracking and Pupil Dilation to Understand Truth Telling and Deception in Sender-Receiver Games. American Economic Review 100, 984-1007.

73. Wibral, M., Dohmen, T., Klingmuller, D.,Weber, B., Falk, A. (2012). Testosterone administration reduces lying in men. PLoS One 7 (10), e46774. 